\title{
Categorizando Usuários "Fáceis" e "Difíceis": Práticas Cotidianas de Implementação de Políticas Públicas e a Produção de Diferenças Sociais
}

\author{
Gabriela Spanghero Lotta ${ }^{1}$ \\ Roberto Rocha Coelho Pires² \\ ${ }^{1}$ Professora e pesquisadora de Administração Pública e Governo da Fundação Getulio Vargas (FGV). São \\ Paulo, SP. Brasil. \\ E-mail: gabriela.lotta@gmail.com. ORCID: http://orcid.org/0000-0003-2801-1628. \\ ${ }^{2}$ Pesquisador do Instituto de Pesquisa Econômica Aplicada (IPEA). Brasília, DF. Brasil. \\ E-mail: roberto.pires@ipea.gov.br. ORCID: https://orcid.org/0000-0001-9392-949X
}

\section{INTRODUÇÃO}

\begin{abstract}
A s experiências cotidianas de interação com os programas do governo, os serviços públicos e os agentes encarregados de sua provisão são repletas de potencialidades, positivas e negativas, para os cidadãos. Acolhimento, dignidade e exercício de direitos, humilhação, destrato, demora e desamparo são exemplos das reações diversas provocadas por estes encontros. Essas interações são importantes não apenas porque abundam nas trajetórias das pessoas em sociedades modernas, uma vez que o processo de construção social do sujeito é mediado por operações de registro, ordenamento, classificação e prestação de serviços voluntários (e.g. acesso à saúde) e involuntários (e.g. tributação e segurança pública) desempenhadas ordinariamente por agentes estatais. Mas também porque essas ligações entre indivíduos e Estado, tal como propôs Norbert Elias (1994), são "cadeias de interdependência" que provêm recursos materiais e simbólicos aos indivíduos, e interferem na identificação destes com um "nós" coletivo. Os serviços públicos são elos dessas cadeias. As interações que
\end{abstract}

\footnotetext{
* Os autores gostariam de agradecer os comentários dos pareceristas anônimos e de Maria Paula Gomes dos Santos e Jonas Nepomuceno, que aportaram valiosas contribuições para este artigo. Agradecemos também à Fapesp (Fundo de Amparo à Pesquisa do Estado de São Paulo) pelo financiamento da pesquisa (processo 2017/24750-0) e aos pesquisadores do Núcleo de Estudos da Burocracia (NEB) pelo auxílio na coleta dos dados.
}

DADOS, Rio de Janeiro, vol.63(4): e20190112, 2020.

https://doi.org/10.1590/dados.2020.63.4.219 
concretizam a provisão de serviços no cotidiano estão no centro de um processo político-moral que entrelaça o reconhecimento e a atribuição de status público pelas instituições aos sujeitos, e as representações que estes sujeitos formam sobre tais instituições (Siblot, 2006).

As práticas cotidianas ${ }^{1}$ dos trabalhadores do Estado e suas interações com o público são o objeto de estudo privilegiado do campo de implementação de políticas públicas, sobretudo em sua variante que enfatizou o papel das "burocracias de nível de rua" (Lipsky, 2010). Estes burocratas são caracterizados como todos aqueles que interagem cotidianamente com usuários para entrega de serviços, como, por exemplo, professores, policiais, assistentes sociais, e trabalhadores da saúde. Essa literatura avançou bastante nas últimas décadas e tem contribuído para ampliar o entendimento sobre usos da discricionariedade por parte dos agentes de implementação e impactos daí derivados sobre as políticas públicas, envolvendo tanto a inovação quanto o desvirtuamento (Pires, 2009; Brodkin, 2012; Hill e Hupe, 2014; Hupe, Hill e Buffat, 2015). Já sabemos que a implementação é mais do que apenas uma coleção de atos administrativos, e que nela transcorre "a política das políticas públicas" (Brodkin, 1990), uma vez que "burocratas do nível da rua" tomam decisões importantes (Lipsky, 2010). Consequentemente, as políticas públicas só obtêm sua substância e forma finais no "encontro burocrático" (Goodsell, 1981). Porém, apesar dos avanços, reconhecemse lacunas importantes no que diz respeito às relações entre práticas cotidianas de implementação de políticas e processos mais amplos de reprodução de desigualdades sociais (Brodkin e Majmundar, 2010), especialmente quando a implementação se desenvolve em estruturas de relações sociais tão desiguais, como no caso brasileiro.

Este artigo pretende contribuir nesta direção buscando compreender as práticas cotidianas adotadas por agentes envolvidos em processos de implementação - em interação direta com os públicos-alvo das políticas $^{2}$-, e de que forma estas práticas promovem a diferenciação social dos atendidos. Em linha com Lamont $(1992,2000)$ e Lahire (2003), reconhecemos a distinção entre diferença social e desigualdade social, assim como os nexos importantes que se estabelecem entre essas categorias. Assim, abordaremos os processos de construção de fronteiras simbólicas, associados à diferenciação entre segmentos do público atendido, em operação nos atos cotidianos de implementação. Tomamos tais fronteiras simbólicas, por sua vez, como condição necessária - embora insuficientes - para a construção de fronteiras (ou 
desigualdades) sociais (Lamont, 2017), pois podem contribuir para a perpetuação de dinâmicas já existentes de exclusão, desatenção ou tratamento inadequado em relação a grupos sociais submetidos a situações de vulnerabilidade.

Para alcançar esse propósito, desenvolvemos neste artigo dois esforços articulados. Primeiro, uma sistematização da literatura sobre implementação de políticas públicas com foco no papel dos agentes envolvidos, visando revelar diferentes perspectivas analíticas que permitam pensar as conexões entre as práticas cotidianas desses agentes e a produção institucional da diferenciação social no acesso a - ou usufruto de - serviços públicos. Segundo, colocamos os argumentos desse debate em diálogo com o estudo empírico da implementação da Estratégia Saúde da Família (ESF) no município de São Paulo, com foco na atuação dos Agentes Comunitários de Saúde (ACS) e suas interações com o público atendido. O estudo se baseou em entrevistas e na análise das narrativas desses agentes sobre suas rotinas de trabalho, a forma como constroem representações sobre os usuários, e como essas representações influenciam suas práticas cotidianas.

A análise dos dados revela como as diferenças sociais penetram o mundo das políticas públicas por meio da centralidade de práticas de categorização e julgamento dos usuários dos serviços pelos agentes envolvidos na implementação. Isso ocorre especialmente em contextos marcados por restrições de recursos/capacidade, e junto a públicos submetidos a variadas formas de vulnerabilidade. Essas categorizações e julgamentos constituem um esforço de delimitação de fronteiras simbólicas (Lamont, 2000), o qual permite aos agentes operarem uma segmentação informal (não oficial) do público atendido baseada na diferenciação de "usuários fáceis" e "usuários difíceis". Os achados indicam que essa diferenciação social mescla elementos de natureza funcional (i.e., formas de fazer o trabalho dar certo sob condições adversas) com elementos morais associados a uma avaliação sobre a (in)adequação do comportamento dos usuários (i.e., motivação, adesão, docilidade). Por fim, discutimos as possíveis repercussões dessas práticas de implementação para o enfrentamento de desigualdades sociais já existentes. $\mathrm{O}$ desafio envolve romper com um ciclo de acumulação de desvantagens, a partir do qual os grupos sociais já submetidos a situações de vulnerabilidade podem ser classificados como usuários difíceis e, consequentemente, encontrar obstáculos adicionais no acesso ou na qualidade dos serviços públicos. 


\section{PERSPECTIVAS ANALÍTICAS SOBRE A RELAÇÃO ENTRE PRÁTICAS COTIDIANAS DE IMPLEMENTAÇÃO E A PRODUÇÃO DE DIFERENÇAS SOCIAIS}

Reconhecendo os avanços recentes no debate nacional em torno do estudo das práticas, modos de gestão, e gramáticas morais da operação cotidiana das burocracias públicas (Brito e Schuch, 2019; Pires, 2019), procuramos acrescentar uma sistematização de aportes teóricos tipicamente associados ao campo da implementação de políticas públicas no debate internacional. Assim, nesta seção, buscamos sistematizar partes da literatura sobre o papel dos agentes envolvidos em processos de implementação, visando identificar perspectivas analíticas que nos auxiliem a pensar possíveis relações entre as práticas cotidianas dos agentes implementadores e a produção de diferenças sociais. $\mathrm{O}$ propósito foi compreender como as interseções entre esses elementos são tratadas por três diferentes correntes que se dedicaram a estudar a atuação dos trabalhadores de linha de frente no serviço público. A seguir, discutimos cada uma dessas três perspectivas, visando orientar a análise subsequente, assim como pesquisas futuras sobre o tema.

Condições de trabalho, decisões discricionárias e os seus efeitos sobre o público atendido

Uma tradição há muito estabelecida, que se baseia em estudos da sociologia jurídica, da implementação de políticas e da administração pública, dedicou-se à reflexão sobre os efeitos dos usos da discricionariedade pelos trabalhadores situados nos níveis mais baixos da hierarquia administrativa (Wilson, 1968; Davis, 1969; Lipsky, 1969, 2010; Silbey, 1981). Enquanto alguns enfatizaram desafios para o controle hierárquico e a prestação de contas (Hupe e Hill, 2007; Pires, 2011), outros apontaram que os usos da discricionariedade poderiam ter efeitos distributivos e levar os serviços públicos a oferecer acesso, tratamento e atenção desiguais ao público (Goetz, 2001; Korteweg, 2003; Rosenthal e Peccei, 2005).

Em outras palavras, o comportamento discricionário começou a ser visto como contraditório ao princípio burocrático do tratamento isonômico com base em critérios não prescritos pela lei ou comando superior. As práticas cotidianas destes burocratas criam padrões diferenciais de distribuição de bens e serviços públicos. As decisões discricionárias e o 
tratamento desigual resultante poderiam, então, ser entendidos como potenciais contribuintes para reforçar as desigualdades sociais existentes em vez de colaborar para mitigá-las (Brodkin e Majmundar, 2010).

Essa perspectiva é bem representada pelo trabalho seminal de Lipsky (2010), no qual retrata os "burocratas de nível de rua" (BNR) como atores racionais que buscam sua autopreservação ao lidar com condições de trabalho caracterizadas por complexidade, escassez e imediatismo. Eles geralmente atuam sob condições de trabalho estressantes e adversas, envolvendo demandas excessivas, recursos escassos e regras ambíguas que elevam incertezas sobre o que deve ser feito.

Sob essas condições, e muitas vezes trabalhando longe da vigilância de seus superiores, os BNR desfrutam de discricionariedade e adaptam objetivos gerais, regras formais e comandos hierárquicos às situações concretas e específicas que enfrentam no dia a dia. Assim, em resposta às circunstâncias frequentemente inadequadas sob as quais trabalham, usam a discricionariedade como meio de obter maior controle sobre suas rotinas. Reorganizam a maneira de realizar o trabalho a fim de domesticar as demandas, tornar suas cargas de trabalho factíveis e gerenciar o fluxo de atividades (Lipsky, 2010).

Esse raciocínio serviu para importantes desenvolvimentos conceituais trabalhados nessa corrente da literatura, tais como: a) coping, entendida como mecanismos para lidar com incertezas, estresse e exigências psicológicas do trabalho, permitindo domínio do fluxo de atividades por meio do racionamento de serviços e da seleção, triagem e priorização de clientes (Lipsky, 2010; Nielsen, 2006; Tummers et al., 2015); b) creaming, um tipo especial de racionamento de serviços que envolve priorização de casos fáceis, bem definidos e com maior propensão de sucesso, e protelação dos mais complicados ou indesejáveis (Lipsky, 2010; Nielsen, 2006); e c) gatekeeping, associado às modificações das concepções de clientes, por parte dos trabalhadores, às reinterpretações da elegibilidade dos usuários e ao desenvolvimento de critérios informais, ou imposição de custos adicionais no acesso a bens e serviços (Lipsky, 2010; Brodkin e Majmundar, 2010; Ellis, 2011).

Esses conceitos permitem reconhecer os padrões de prática desenvolvidos pelos BNR, à medida que adaptam informalmente a condução do seu trabalho face às regras, estruturas e situações formais sob as quais operam. Como afirma Lipsky: 
pode haver pouco reconhecimento oficial de que o viés existe quando ele é burocraticamente funcional. Clientes e cidadãos envolvidos percebem um comportamento tendencioso. Já os burocratas do nível de rua enxergam atitudes forjadas a partir da experiência e reforçadas diariamente em função de sua eficácia. Enquanto clientes veem injustiça, burocratas do nível de rua veem respostas racionais às necessidades burocráticas (Lipsky, 2010:116).

Assim, mesmo que a motivação dos burocratas seja contornar desafios que emergem no seu cotidiano e recuperar o controle do fluxo de trabalho, a adoção dessas práticas pode levar a uma distribuição desigual do acesso ao serviço público ou da qualidade do atendimento, favorecendo alguns indivíduos em detrimento de outros. No limite, em contextos de elevada desigualdade social, essa prática pode fazer com que pessoas mais necessitadas e vulneráveis sejam deixadas sem atendimento ou precisem esperar mais tempo para acessar bens ou serviços públicos. Em suma, o comportamento discricionário dos trabalhadores do setor público, em resposta às condições sob as quais atuam, fornece um prisma através do qual podemos ver como práticas de implementação interagem com processos de diferenciação social, podendo contribuir para dinâmicas mais amplas de reprodução de desigualdades sociais.

Porém, essa é uma perspectiva que trabalha a relação entre implementação, diferenciação social e desigualdades de maneira muito limitada. O primeiro problema é que ela incorpora a desigualdade social como apenas resultado potencial da tomada de decisão discricionária no "nível de rua". Ao fazê-lo, deixa de perceber essa desigualdade como algo que pode estar enraizado na política ou no próprio processo de implementação, como precondição ou elemento constitutivo para os encontros entre trabalhadores e o público a quem servem.

A partir dos anos 2000, essas limitações começaram a ser abordadas por meio de trabalhos que passaram a olhar não apenas para efeitos da ação discricionária, mas também para as interações dos burocratas com os usuários. Esses estudos têm buscado situar socialmente a ação dos trabalhadores do nível de rua e reformular a concepção de implementação de políticas como um processo essencialmente interativo (Winter, 2003; Durose, 2011; Harrits e Moller, 2013; Moller e Stone, 2013; Portillo e Rudes, 2014; Thomann e Rapp, 2018). Essas obras evidenciam o esforço de transição de uma percepção funcional mais tradicional do comportamento dos agentes no nível de rua para uma 
perspectiva mais sociológica. Buscaram compreender as construções sociais existentes na implementação das políticas públicas e como essas construções afetam o acesso dos beneficiários aos bens e serviços. Trata-se de um esforço que passa a perceber os agentes envolvidos em processos de implementação como dependentes de múltiplos atores sociais e, mais importante, como tais interdependências podem afetar a construção e o desempenho de seus próprios papéis (Silbey, 2011). Assim, essas pesquisas têm contribuído para o desenvolvimento de uma atenção mais detida sobre como a atuação desses agentes pode repercutir em diferentes formas de exclusão e inclusão, tanto no plano material quanto no simbólico.

Categorizações, julgamentos morais e reprodução de valores, normas e posições sociais

Analisando as decisões discricionárias dos "burocratas do nível de rua", Lipsky (1980) chama atenção para a influência de valores e normas sociais na definição dos possíveis cursos de ação frente aos desafios envolvidos no trabalho de implementação. Segundo o autor, ainda que os BNR se deparem com situações potencialmente novas, que demandam adaptações das regras e procedimentos, as respostas possíveis a estas situações não são infinitas, mas tendem a se limitar aos valores e normas reconhecidas como prevalecentes na sociedade, na categoria ocupacional, ou na própria organização em que trabalham.

Porém, essa perspectiva ganha maior impulso nos trabalhos de Maynard-Moody e Musheno $(2003,2012)$. Estes sugerem que é importante distinguirmos duas formas de compreender a atuação dos agentes envolvidos em processos de implementação. A primeira é pensar que o uso da discricionariedade serve para adaptar leis, regras formais e objetivos da política às situações locais - perspectiva que denominam stateagent narrative, na qual localizam a argumentação construída por Lipsky (2010). Porém, defendem que essa forma seria insuficiente, propondo um deslocamento do foco da "orientação a regras" para a "orientação a faces", dando ensejo à orientação alternativa que denominam citizenagent narrative. Segundo esta orientação, regras e procedimentos formais oferecem apenas constrangimentos fracos sobre os julgamentos na linha de frente. Em vez de se apoiar em regras para guiar suas decisões, os agentes primeiramente atribuem identidades aos usuários para então formar julgamento sobre "quem são os merecedores". Somente em 
seguida os agentes se voltariam para as categorias formais em busca de apoio no encaminhamento ou justificação técnica dos julgamentos morais e identitários feitos. Assim,

os trabalhadores se concentram em definir quem as pessoas são, em relação às visões imaginadas que constroem sobre o público, e impõem a elas uma conformidade cultural, em sobreposição a uma obediência legal (2012:S17).

Essa perspectiva percebe os usos da discricionariedade como um processo moralmente complexo, no qual uma racionalidade baseada em identidades define como as regras, procedimentos e políticas são colocados em ação; ou quem acessa quais serviços e quem é ignorado. Nesse sentido, aproxima a atuação cotidiana dos agentes encarregados da implementação da ideia de um esforço contínuo de construção de fronteiras simbólicas (boundary work), tal como proposto por Lamont $(1992,2000)^{3}$. Pois, compreender como os julgamentos de valor a respeito dos usuários dos serviços são feitos oferece uma "janela" analítica para melhor entender a produção de diferenças sociais em processos de implementação.

Valores, normas sociais e preconceitos frequentemente incorporam definições coletivamente compartilhadas de status e posições relativas de grupos sociais. Assim, sua mobilização em julgamentos de usuários de serviços, pelos agentes envolvidos na implementação pode levar à persistência de representações culturalmente sancionadas de merecimento ou desprezo (Harrits, 2019). Epp, Maynard-Moody e Haider-Markel (2014) demonstraram, a partir de estudo sobre abordagens policiais nos EUA, como práticas de diferenciação do público atendido pelos agentes estavam frequentemente associadas a clivagens raciais, contribuindo para perpetuação da divisão racial daquele país. Em suma, os autores demonstram que processos de implementação se apresentam como lócus de reforço a diferenças sociais já cristalizadas nas culturas locais ou nacionais.

Durante os processos de implementação, agentes mobilizam preconcepções adquiridas ao longo da vida e as utilizam para identificar casos que creem serem merecedores dos benefícios e de seus esforços especiais (Oorshot, 2008; Schneider e Ingram, 2005). Normas e valores partilhados pelos agentes influenciam diretamente a discricionariedade na triagem, classificação dos casos e redefinição de critérios de elegibilidade (Harrits, 2019). Agentes de implementação identificam 
e categorizam as situações baseando-se em impressões e sensações que possuem sobre o mundo e sobre as situações, nas quais muitas vezes prevalecem o senso comum, estereótipos e preconceitos. Para categorizar situações, mobilizam concepções adquiridas em sua vida social e nas suas experiências de trabalho, as quais se transformam em percepções sobre o que é ou não aceitável e sobre quais situações têm maior ou menor merecimento (Harrits e Møller, 2013; Harrits, 2019).

O merecimento dos benefícios oferecidos por uma política pública é uma construção social (Schneider e Ingram, 2005), na qual os agentes de implementação se tornam ativamente engajados em processos de (des)construção de fronteiras simbólicas (Lamont, 1992, 2000) entre grupos atendidos. $\mathrm{O}$ merecimento também pode ser articulado como percepção dos agentes sobre a motivação dos usuários em se engajarem com as atividades propostas pela política pública (Moller, 2016). A apreciação da motivação dos usuários oferece aos agentes uma forma de classificá-los como moralmente superiores e merecedores (ou não) dos investimentos públicos (Tummers, 2017). Assim, por meio de tais classificações, introduz-se um risco para usuários que não são identificados com status e posições de respeito nas hierarquias de valores sociais, ou não são percebidos como suficientemente engajados ou motivados. Pois, para estes, podem ser impostas dificuldades adicionais ou barreiras no acesso aos benefícios e serviços públicos.

\section{As consequências simbólicas das interações entre agentes e usuários}

Enquanto a perspectiva anterior enfatizou normas sociais, valores e traços culturais como elementos que podem predeterminar os julgamentos dos agentes sobre o público, a terceira perspectiva, tributária da sociologia do guichê francesa (Pires, 2017), chama atenção para situações de interação dos agentes envolvidos em processos de implementação e os usuários das políticas. É um enfoque que explora os encontros cotidianos como situações que podem afetar o sentido de lugar, posição e estima social dos usuários (Dubois, 1999; Siblot, 2006).

Essa perspectiva tem raízes no interacionismo simbólico e em outras teorias microssociológicas, que consideram que encontros cotidianos possuem algum nível de autonomia e criatividade em relação a outros níveis da realidade social (como organizações, cultura e sociedade). Tal como proposto por Goffman (1961), atores sociais coproduzem (constroem conjuntamente a partir da interação) o sentido e a inte- 
ligibilidade da situação de interação por meio de um processo de "reparação", ajustando seus papéis sociais e intenções à medida que a interação se desenvolve. A ideia é que as interações necessariamente envolvem tensões latentes, incertezas e instabilidades que precisam ser resolvidas pelos atores para que alcancem uma definição comum da situação. Nessa linha, interações com agentes de implementação e usuários passam a ser entendidas através da lente da "coprodução", que remete à mútua dependência dos atores para a ação se concretizar. Isso implica que o processamento de casos requer acordos e alinhamentos sucessivos entre burocratas e usuários, em termos de como as informações sobre a vida dos últimos são traduzidas pelos primeiros nas categorias legais-administrativas disponíveis (Weller, 1999).

Entretanto, como interações dos funcionários do serviço público e usuários se desenrolam em contextos de desigualdades sociais preexistentes, as capacidades destes atores de influenciar e coproduzir essas situações são desequilibradas. Há uma assimetria inevitável nas interações que fazem parte da implementação de políticas (Dubois, 1999). Por um lado, usuários frequentemente dependem dos bens e serviços fornecidos pelo governo para garantir sua sobrevivência. Por outro, opacidade administrativa, carência de conhecimento e incertezas relativas ao acesso fazem com que os usuários dependam também da boa vontade dos agentes no processamento dos seus casos. Consequentemente, usuários encontram-se em uma situação de dependência estrutural em relação às políticas públicas e seus trabalhadores. Essa dependência faz com que interações que deveriam ter um caráter apenas administrativo adquiram um status de reconstrução simbólica do usuário.

A simples aplicação de categorias administrativas transforma-se em um processo de atribuição de status, por meio do qual o aprendizado do usuário a partir da relação administrativa se aproxima de sua reeducação sobre as normas da vida social (Dubois, 1999:138).

O controle das identidades é uma das formas pelas quais podemos perceber as consequências simbólicas das interações de implementação sobre os usuários. Os agentes engajados em atividades de implementação buscam enquadrar usuários em formulários, sistemas e categorias preestabelecidas. Em muitas situações, usuários não apenas se sentem coagidos a concordar com a categorização imposta pelos agentes (pois é condição de acesso a benefícios), mas podem também 
internalizá-la como elemento de interferência em suas identidades ou reforço a sua suposta "anormalidade", estigma ou baixa estima social. Ao construir os perfis administrativos dos usuários, a partir de uma posição de dominância, agentes de implementação podem incorrer em práticas de violência simbólica e interferir no entendimento do usuário sobra sua posição e valor social, impondo a eles uma interpretação sobre sua existência na sociedade. Assim, interações dos trabalhadores da linha de frente do serviço público e usuários podem perpetuar posições sociais subordinadas em relações estruturais de dominação (Bourdieu, 1972) e reproduzir identidades sociais estigmatizadas.

Em resumo, esta perspectiva, de cunho interacionista, percebe os encontros entre agentes de implementação e usuários como um processo de coprodução de serviços, na medida em que requerem consentimento sobre como processar os casos. Entretanto, dado que tal coprodução se desenvolve em meio a assimetrias de poder, a "concordância" dos usuários sobre a tradução administrativa de sua intimidade não é imune a consequências simbólicas. Estas incluem potenciais interferências negativas nas formas como os usuários passam a se identificar e perceber suas posições e valores na sociedade, assim como àquilo que se sentem portadores de direito, contribuindo para o reforço e perpetuação de formas de exclusão social.

Apresentamos acima três perspectivas que nos auxiliam a pensar as relações entre o trabalho cotidiano dos implementadores e a produção de diferenças sociais, a partir de diferentes ângulos e possibilidades de explicação. A primeira perspectiva chamou atenção para como as decisões discricionárias - e seus potenciais efeitos distributivos - são influenciadas pelo contexto e pelas condições dentro das quais o trabalho dos implementadores é desempenhado. Contextos adversos, em que se somam escassez de recursos e abundância de demandas, tendem a favorecer posturas de autopreservação e creaming, com a priorização dos casos mais fáceis ou com maior probabilidade de sucesso. A segunda perspectiva acrescentou que as decisões e ações dos agentes envolvidos nos esforços de implementação não são apenas orientadas por uma reação às condições de trabalho, mas, principalmente, por valores e normas sociais sobre os quais se apoiam processos de categorização e julgamento moral, permitindo a segmentação do público atendido entre merecedores e não merecedores. Por fim, a terceira perspectiva enfatizou as interações dos trabalhadores com os usuários de serviços como um processo de coprodução que impõe algum grau de 
negociação (flexibilidade) aos processos de categorização e julgamento, em função das ações e comportamentos dos usuários no decorrer das relações de serviço. A seguir, mais do que colocar estas perspectivas em contraste, buscaremos colocar os seus diferentes insights em diálogo com a análise empírica de um caso envolvendo a atuação dos Agentes Comunitários de Saúde.

\section{ANALISANDO AS NARRATIVAS DE AGENTES COMUNITÁRIOS DE SAÚDE: DESENHO DE PESQUISA E MÉTODOS}

Orientados pelas perspectivas teóricas delineadas na seção anterior e com o objetivo de examinar como práticas cotidianas de implementação se entrelaçam com processos de construção de diferenças sociais, conduzimos um estudo empírico da implementação da Estratégia de Saúde da Família (ESF), com foco na atuação dos Agentes Comunitários de Saúde (ACS). Abaixo, apresentamos o caso estudado e as técnicas de pesquisa e análise empregadas.

\section{Agentes Comunitários de Saúde na Estratégia Saúde da Família}

A ESF faz parte de um conjunto de medidas do Sistema Único de Saúde (SUS) voltadas a reorganizar a atenção básica à saúde (Menicucci e Marques, 2016). Ela oferece serviços no domicílio, investindo na humanização do tratamento, na compreensão dos problemas de saúde dentro dos contextos sociais e na identificação de fatores de risco associados às condições de habitação e vida das famílias (Silva e Dalmaso, 2002). A política é executada por equipes multiprofissionais, formadas por médicos, enfermeiros, auxiliares de enfermagem e ACS. O ACS é selecionado na comunidade onde executa seus trabalhos e é responsável por cuidar da saúde de cerca de 200 famílias que vivem sob sua área de responsabilidade. Em sua prática cotidiana, têm como função acompanhar as famílias, verificar suas condições de vida, dar orientações e intermediar informações entre a equipe de saúde e os usuários. Trata-se de uma política pública consolidada e difundida em todo território nacional. O programa atende a cerca de $65 \%$ da população brasileira e há atualmente mais de 240 mil ACS no Brasil que realizam aproximadamente 44 milhões de visitas domiciliares por mês em todo país (Ministério da Saúde, 2018). 
De acordo com as orientações formais da ESF, o trabalho desses ACS deve ser pautado pelas ideias de corresponsabilidade, autonomia e cogestão. O serviço deve ser configurado com base em "um novo modo de agir em saúde, em que as responsabilidades pelos cuidados passam a ser compartilhadas pelas famílias e pelas equipes de saúde da família" (Gelinski, 2011:1). A política tem como objetivo “(...) o estabelecimento de vínculos e a criação de laços de compromisso e de corresponsabilidade entre os profissionais de saúde e a população" (Brasil, 1997:7).

Essas características implicam no engajamento de ACS e usuários em um processo de coprodução ${ }^{4}$ do serviço. Tal como descreve Weller (1999), os encontros entre agentes de implementação e usuários dos serviços envolvem uma tensão latente, um confronto de discursos e, consequentemente, incertezas e instabilidades. O usuário, de um lado, exprime suas expectativas e crenças quanto à natureza da sua demanda e situação particular. Do outro, o agente apresenta suas definições de realidade e as possibilidades de categorização previstas no serviço. Trata-se de um encontro que produz tradução, definição comum, ou equivalência entre as situações singulares dos demandantes e as categorias jurídicas, administrativas e financeiro-contábeis formalmente previstas na política pública. Nesse sentido, a implementação da ESF no cotidiano é parcialmente dependente das ações e do trabalho dos ACS (visitas domiciliares, escuta dos usuários, intermediação com os profissionais de saúde etc.), e parcialmente dependente dos comportamentos, condutas e atitudes dos usuários (receber ACS em suas casas, fornecer informações, seguir recomendações médicas, comparecer às consultas e exames agendados etc.).

Essas relações de coprodução são facilitadas por dois fatores. Primeiro, por morarem na mesma comunidade das famílias atendidas e representarem uma forma de "agente híbrido" - sendo simultaneamente servidor público e membro da comunidade ${ }^{5}$ - os ACS carregam uma potencial capacidade de mediação entre os usuários da política e demais profissionais da equipe (Lotta, 2015), pois habitam ambos os mundos simultaneamente. Além disso, os ACS dispõem de um elevado grau de discricionariedade no exercício de suas funções, o que lhes permite mobilizar um conjunto variado de práticas, considerando sua inserção na comunidade e as relações prévias com os cidadãos (Lotta, 2015; Nunes e Lotta, 2019; Reinehr, 2019). 
No entanto, há também desafios não triviais envolvidos na ativação dessa corresponsabilidade por parte dos usuários dos serviços. Ela pressupõe que os atores envolvidos na relação conheçam bem seus papéis, aquilo que podem demandar e aquilo que devem desempenhar. Segundo Gelinski, ao longo da trajetória de implementação da política, não ficou claro

o real sentido da corresponsabilidade prevista pela ESF: foi se delineando a quase impossibilidade de tornar a população corresponsável de um programa que eles desconhecem. Nas entrevistas percebe-se o quanto gritante é o desequilíbrio de saberes sobre o funcionamento do programa e do que pode e não pode ser cobrado dele (Gelinski, 2011:108).

Outro desafio diz respeito às condições sociais dos usuários dos serviços. Em condições de elevada vulnerabilidade social, a probabilidade de que as famílias atendidas consigam desempenhar a contento as condutas esperadas é consideravelmente reduzida. Isto é, em situações de vida marcadas por precariedades, apresentar-se em locais e horas marcadas para consultas ou exames, cumprir as prescrições médicas ou evitar situações de conflito, por exemplo, podem se tornar tarefas inexequíveis.

Assim, a implementação da ESF, atravessada pelo princípio da corresponsabilidade, torna-se um objeto de estudo interessante, dados os desafios envolvidos em sua concretização e as implicações dessas dinâmicas de construção de vínculos sobre o trabalho dos ACS e sobre os pacientes atendidos (Reinehr, 2019). O estudo desse caso pode, portanto, revelar como os ACS lidam com essas situações no seu trabalho, e como suas práticas cotidianas repercutem sobre os usuários dos serviços.

Esse tipo de dinâmica está longe de ser uma particularidade da ESF e dos ACS. As ações governamentais no campo das políticas sociais são, em geral, caracterizadas pela intensidade de mão de obra e pelo grande volume de interações dos trabalhadores do serviço público e seus usuários. A provisão dos serviços requer esses contatos (presenciais ou virtuais) por meio dos quais se articulam, em regime de coprodução, as situações de vida das pessoas e as tipificações de bens e serviços oferecidos. Assim, a questão da corresponsabilização coloca-se em um conjunto amplo de políticas e serviços - por exemplo, na relação entre professores e alunos, e nas políticas de distribuição de renda 
condicionada. A corresponsabilidade aparece de forma mais explícita em serviços públicos ancorados no desejo de promover autonomia e emancipação dos seus usuários, como nos casos de políticas de assistência social, ancoradas numa perspectiva de direito social ${ }^{6}$, ou da atenção a usuários problemáticos de substâncias psicoativas nos Centros de Atenção Psicossocial Álcool e Drogas (CAPS-AD) (Worcman e Morganti, 2019). Em todos esses casos: a) o desafio de produzir a adesão e vinculação dos usuários aos serviços ou tratamentos é central; b) as condições para ativação da corresponsabilidade dos usuários são frequentemente precárias; e c) os riscos associados às expectativas e julgamentos dos comportamentos dos usuários se fazem presentes. Assim, o estudo da ESF e dos ACS lança luzes sobre dinâmicas e processos cuja análise pode revelar interpretações e achados relevantes para reflexão sobre outras experiências de implementação de políticas e serviços públicos.

\section{Técnicas de pesquisa e análise empregadas}

Para analisar o caso da implementação da atuação dos ACS realizamos, entre 2016 e 2017, entrevistas com 77 agentes atuantes em 11 Unidades Básicas de Saúde (UBS) de diferentes regiões no município de São Paulo, caracterizadas por alta vulnerabilidade social - já que nos interessa compreender, em especial, as relações cotidianas entre agentes de implementação e segmentos vulneráveis da população. Foram entrevistados entre 4 e 10 ACS de cada UBS, considerando a disponibilidade para participar da pesquisa e os critérios para induzir a diversidade da amostra (faixa etária, tempo de serviço, formação inicial e outras formações em saúde).

As entrevistas foram semiestruturadas, com roteiro em quatro partes: a) perfil, trajetória e formação; b) percepção sobre o trabalho, relação com equipe e usuários; c) questões sobre usuários fáceis e difíceis de atender; e d) histórias de sucesso e de fracasso. O desenvolvimento do instrumento se inspirou nos trabalhos de Maynard-Moody e Musheno (2003) que analisaram processos de julgamento de burocratas a partir de narrativas. $\mathrm{O}$ uso de narrativas permite analisar como burocratas convertem uma política geral em práticas cotidianas que constituem a realidade da política implementada (Maynard-Moody e Musheno, 2012) ${ }^{7}$. 
A amostra não é estatisticamente representativa. A escolha dos entrevistados seguiu a estratégia de seleção estratificada não randômica (ou sampling for range), segundo a qual o pesquisador identifica subcategorias do grupo sob estudo - como unidades organizacionais/ território, tempo de serviço e formação no trabalho, já apontadas como relevantes pela literatura - e assegura a diversidade dos respondentes a partir dessas características (Trost, 1986; Small, 2009). Essa estratégia permitiu acesso a uma variedade de narrativas dos ACS sobre o cotidiano do seu trabalho e suas percepções sobre os usuários. Este material mediou nossa aproximação aos processos de construção de representações sociais sobre os usuários, por parte desses agentes; e sobre como essas representações conformam sistemas de classificação associados a julgamentos morais que informam práticas concretas na provisão cotidiana dos serviços. As narrativas coletadas dão concretude e vivacidade a esses processos e serão utilizadas como fundamentos da análise a seguir'. Elas são também a base para compreensão das interações, analisadas aqui a partir dos relatos dos ACS sobre seus encontros com os usuários do serviço.

Com relação ao perfil dos respondentes, dos 77 ACS entrevistados, 71 eram do sexo feminino e apenas seis do sexo masculino. Os entrevistados estão em média há 5 anos e 2 meses envolvidos com o serviço e moram na região da UBS em que atuam há 18 anos e 7 meses. Questionados sobre a motivação para entrada no trabalho, apenas 5 dos 77 entrevistados alegaram que desejavam trabalhar na área de saúde, e 16 entraram por gostarem de atividades comunitárias. Os demais entraram pela proximidade com a moradia ou pela oportunidade de emprego. Com relação à formação no serviço, 43 dos 77 entrevistados receberam algum tipo de capacitação e apenas 11 participam de associações comunitárias ou movimentos sociais, o que contradiz a história associativista do programa, mas reforça achados anteriores sobre perfil de contratação de organizações sociais na saúde (Lotta, 2015). Com relação à religião, 53 deles são frequentadores de alguma igreja, sendo 27 - quase a metade - de igrejas evangélicas.

Dado o perfil dos entrevistados, seria razoável supor que possa haver variações internas nas percepções e práticas relatadas, em termos de subgrupos de ACS. Porém, neste artigo, nos deteremos na compreensão dos padrões mais gerais e transversais de categorização adotados pelos ACS em sua lida cotidiana com o público atendido. 


\section{CORRESPONSABILIZAÇÃO, OPERAÇÕES DE CATEGORIZAÇÃO E SUAS REPERCUSSÕES PARA OS USUÁRIOS DE SERVIÇOS DE SAÚDE}

Nesta seção organizamos os resultados da análise em três momentos. Primeiro, abordamos como o contexto de implementação analisado, envolvendo limitações de recursos por parte do serviço e vulnerabilidades por parte do público, cria condições propícias para que os agentes passem a incorporar a avaliação do comportamento dos usuários como critério informal para orientar suas ações no atendimento aos mesmos. Em seguida, aprofundamos a discussão sobre os sistemas de categorização e julgamento que lhes permitem diferenciar e caracterizar usuários "fáceis" e "difíceis". Finalmente, discutimos as narrativas dos ACS sobre casos de fracasso e de sucesso, retomando novamente as categorias de usuários "fáceis" e "difíceis" para revelar a natureza dinâmica e negociada do processo de categorização, assim como a delimitação da responsabilidade dos ACS e a culpabilização dos pacientes pelos resultados obtidos.

\section{Corresponsabilização e expectativas sobre os usuários}

Como afirmado, a ESF e a atuação dos ACS são pautadas pelo princípio da corresponsabilidade, cuja efetivação é marcada por desafios e dificuldades práticas. $\mathrm{O}$ estudo das atividades cotidianas de implementação da ESF pelos ACS corroborou essas tendências já apontadas pela literatura (em especial aquelas associadas à primeira e à terceira perspectiva analítica da seção "Perspectivas analíticas sobre a relação entre práticas cotidianas de implementação e a produção de diferenças sociais" deste artigo). Mais do que isso, revelou que, quando a implementação da política se dá em meio à combinação de (a) territórios marcados por situações de elevada vulnerabilidade social, e (b) insuficiência de recursos e de capacidade de enfrentamento da ampla demanda, criam-se condições propícias para a incorporação de critérios informais nas práticas cotidianas dos ACS, baseados em suas expectativas e avaliações sobre o comportamento dos usuários frente ao serviço. No que segue abaixo, abordaremos esses dois condicionantes da implementação, assim como as implicações da sua combinação.

No que toca aos territórios, todas as UBS onde entrevistamos ACS têm sua área de abrangência caracterizada por altos índices de vulnerabilidade social - isto é, mais de $30 \%$ de vulnerabilidade, segundo o 
Índice Paulista de Vulnerabilidade Social (Fundação Seade, 2010). São também regiões com Índice de Desenvolvimento Humano Municipal (IDHM) inferior à média municipal de São Paulo. Isso significa que são territórios marcados por carências de infraestrutura urbana (água, esgoto, coleta de lixo, mobilidade etc.), e majoritariamente habitados por famílias com níveis relativamente baixos de renda e escolaridade. Ainda assim, mesmo nesses territórios de alta vulnerabilidade existem gradações nas condições de vulnerabilidade vividas pelos cidadãos, estando alguns usuários sujeitos a condições mais precárias que outros.

Para além da caracterização a partir dos indicadores, as narrativas dos ACS reforçam a percepção da situação de vulnerabilidade da população atendida nesses territórios.

Eu acho que elas [as famílias] são muito carentes, carentes de atenção, carentes de informação, porque... Eu não sei se é por falta de instrução, de estudo... muita gente que no máximo concluiu ali o ensino médio, e aí eles não têm muita orientação... (E3U5).

A (nome da rua) tem umas áreas de vulnerabilidade. É um morro que é frequentado por usuários de drogas. E esse morro também é atendido por outro tipo de estratégia, né? A agente comunitária visita e vê as vulnerabilidades. Criança em situação de vulnerabilidade e crianças sem higiene pessoal (E5U4).

Não tem tanta coisa assim que a gente orienta na casa, eu não faço porque como são casas carentes, tem coisa que não adianta você orientar, sabe? (E4U8).

Já com relação às restrições de recursos e condições adversas enfrentadas no decorrer do trabalho de atendimento às famílias, os ACS foram assertivos em seus relatos ao chamar atenção para a ausência de estruturas adequadas de prestação de serviços, e a uma demanda que excede as capacidades existentes.

Olha, a reclamação geralmente é falta de vaga para atendimento. A nossa população também é muita, né? Eles são muito carentes. Então às vezes a gente não consegue dar o atendimento que deveria, entendeu? Até por falta de estrutura. Aqui é uma unidade nova. Tá faltando muitas coisas e agora a gente tá numa fase que nem medicamento você acha na farmácia. E a nossa população, a maioria, não tem condição de comprar. (E1U6) 
Às vezes a gente não tem material suficiente pra trabalhar e eu não falo só essa questão do geral. Às vezes a gente precisa do cartão família e tá em falta, aí você precisa entregar pro paciente, não tem. Então as coisas básicas... caneta, lápis, a gente pega lá, mas geralmente a gente compra também, né? Então, se você precisa de uma fita corretiva a gente vai lá e compra (E7U9).

A combinação dessas duas facetas da vulnerabilidade - a social e a institucional - suscita duas repercussões importantes. A primeira diz respeito às dificuldades na efetivação do princípio da corresponsabilidade como diretriz orientadora formalizada nos documentos oficiais sobre o programa. A construção do vínculo com o usuário é condição central para a realização do trabalho desempenhado pelas ACS a tal ponto que "se não conseguir construir vínculo, não dá pra fazer o meu trabalho" (E1U2). Não foram incomuns os relatos sobre estratégias desenvolvidas para tal:

Eu criei um método de trabalho em que eu não sou a agente comunitária, eu sou a Andrea, a vizinha, a que traz as informações e a que leva. Se não, eu não conseguiria trabalhar e teria enlouquecido. Então, a gente se trata como amigos mesmo. É uma conversa de amigos, assim consigo que eles se tratem $(\mathrm{E} 4 \mathrm{U} 3)$.

A segunda repercussão, também derivada das dificuldades enfrentadas na construção de vínculos, diz respeito à tendência das ACS de incorporarem expectativas e avaliações do comportamento de seus atendidos como um critério informal de seleção dos beneficiários de suas ações. Dado que a construção de vínculo é entendida como requisito essencial à boa execução dos serviços, as agentes passam a avaliar os usuários em termos de suas propensões à adesão e à cooperação (tal como sugerido pela noção de creaming). Neste sentido, as ACS confirmam que o desempenho do seu trabalho é parcialmente dependente dos comportamentos dos usuários, reforçando a percepção do engajamento de ambos em um processo de coprodução do serviço (Weller, 1999). Em um contexto no qual somam-se as precariedades dos serviços e as dos usuários, esta é uma forma que permite às ACS tentarem, minimamente, exercer controle sobre a parte da relação que não lhes cabem diretamente: a cooperação do paciente. 
A análise das entrevistas tornou evidente que as expectativas das ACS sobre o comportamento dos usuários frente ao serviço passam a ser utilizadas como critério informal para decidir quem merece, ou não, receber o serviço, ou receber atendimento de melhor qualidade. Isto é, dadas as dificuldades intrínsecas ao seu trabalho, as ACS passam a considerar como mais merecedores de seus esforços e atenção os usuários que melhor se responsabilizam por seu tratamento, que se comportam conforme suas expectativas e fazem a parte deles para o bom andamento dos serviços. Por exemplo, tal como relatada por uma ACS, "depois que aquela família começou a valorizar o meu serviço, eu comecei a passar lá todos os dias" (E3U1). Quando estes não se esforçam o suficiente ante as expectativas de corresponsabilização, as ACS os enquadram como não merecedores de seus melhores esforços enquanto prestadores de serviço, como demonstram os trechos das entrevistas a seguir:

Não depende só de mim, depende deles também. Por exemplo, se eu tenho paciente que tomava medicação e ele desaparece do território, não tem como a gente fazer mais né? Então precisa da gente, e também do esforço deles (E8U11).

Eu já gostei (de trabalhar como ACS), hoje não mais... sabe, quando você já está no seu limite? Porque eu acho que a população... assim, eu tenho direitos e deveres, então eu tenho que fazer a minha parte enquanto funcionária de auxiliar a população. Só que eles também têm que fazer a parte deles como paciente. Só que muitos não fazem, muitos gostam de brigar, muitos gostam de xingar, muitos falam mal do SUS sem o conhecimento, ou não faz a parte deles. E a gente tem incansavelmente que colocar na cabeça da pessoa que não é bem do jeito que ele está falando, né? (...) Eu só acho que “'eu quero, eu quero, eu quero e as coisas que tenho que fazer certinho eu não quero fazer?" O paciente tem esse sentimento, então essa parte é cansativa, de você ficar falando, falando, falando. E a pessoa parece que não entra na cabeça, não entra na cabeça. Aí não dá pra ter paciência com eles (E4U9).

Assim, as expectativas em relação ao comportamento de seus atendidos permitem às agentes segmentarem os serviços que prestam - em níveis de qualidade e esforço empreendido - com base em avaliações sobre a (in)adequação das condutas dos seus usuários. Nesse sentido, emerge o risco de que julgamentos sobre o comportamento e as atitudes dos usuários se combinem ou sobreponham aos critérios formais de elegibilidade do programa, impactando na quantidade e qualidade 
do serviço público prestado para os diferentes grupos. Na próxima seção, buscamos aprofundar a discussão em torno dessas operações de categorização e julgamento.

\section{SISTEMAS DE CATEGORIZAÇÃO E JULGAMENTOS: ENTRE USUÁRIOS FÁCEIS E DIFÍCEIS}

Categorizações são agrupamentos produzidos pelas políticas para ordenar a ação estatal (Harrits e Moller, 2013). Todas as políticas são baseadas em regras de ordenamento do público e das situações (Schneider e Ingram, 2005). Estas regras de ordenamento se materializam na construção de categorias oficiais que diferenciam tipos de cidadãos, direitos, deveres e potenciais encaminhamentos. Elas têm, portanto, papel fundamental na explicação da ação estatal e dos seus efeitos em termos de inclusão e exclusão, já que constroem elegibilidade aos serviços. Mas, embora as políticas sejam baseadas em processos oficiais de categorização, nem sempre os agentes envolvidos na implementação os utilizam desta forma, somando às categorias oficiais outros sistemas informais de categorização, que também repercutem nas decisões sobre elegibilidade e merecimento (Schneider e Ingram, 2005). Sejam de natureza formal ou informal, as formas de categorização dos usuários envolvem julgamentos que permitem justificar a associação de uma determinada categoria com o tipo de situação encontrada (MaynardMoody e Musheno, 2003; Harrits e Moller, 2013).

Para acessarmos os sistemas de categorização e julgamento mobilizados pelas ACS em sua atuação cotidiana, instigamos esses agentes a nos relatar, ao longo das entrevistas, as percepções e representações que constroem sobre os usuários que atendem. A análise do conjunto das entrevistas revelou que sistemas distintos de categorização operam simultaneamente. Um primeiro sistema está diretamente relacionado às categorias oficiais das políticas de saúde: gênero e faixa etária, tipo de doença ou agravo. São categorias como: idosos, crianças, homens, mulheres e adolescentes; hipertensos, diabéticos, puérperas etc. Esse sistema de categorização oficial, baseado na organização proposta pelo serviço, é responsável por uma primeira lógica de enquadramento dos usuários em tipos de tratamento ou encaminhamento. No entanto, quando defrontados com situações reais, mais complexas do que as previstas nas categorias oficiais, os agentes desenvolvem sistemas paralelos de categorização que permitem a tradução das situações concretas encontradas em categorias administrativas. 
Os relatos indicaram que há dois outros tipos de categorização operando separadamente, ou em conjunto com o sistema oficial: categorizações socioculturais e categorizações baseadas em atributos sobre comportamento'. As categorizações socioculturais são aquelas que classificam usuários a partir de perfis sociais, étnicos ou identitários, que não são oficialmente reconhecidos pela política. São exemplos: "os pobres", "os nordestinos", "os nigerianos". As categorizações baseadas em atributos sobre o comportamento se baseiam em avaliações sobre as atitudes dos usuários em face do trabalho a ser desempenhado pelas ACS, como "os desobedientes", "os pacientes agressivos", ou "os usuários que seguem o que a gente recomenda".

Porém, o que mais chamou a atenção, como resultado da análise das entrevistas, diz respeito ao fato de que essa variedade de formas de categorização era frequentemente mobilizada em associação a uma reflexão lastreada em suas experiências de atuação sobre quais eram os "usuários/pacientes fáceis" ou "usuários/pacientes difíceis". Ou seja, os enquadramentos dos usuários nos sistemas de categorização vinham acompanhados da ideia de que certos perfis de usuários são mais cooperativos e aderentes enquanto outros são mais difíceis por imporem alguma forma de resistência ao atendimento ${ }^{10}$ - sendo "cooperativo", "aderente" e "resistente" categorias nativas apresentadas pelos agentes entrevistados. Assim, percebeu-se que, para além de representarem uma diversidade de formas de agrupamentos de usuários, os sistemas de categorização (oficial, sociocultural e comportamental) cumpriam uma função adicional e importante para as ACS: oferecer elementos de descrição, ou uma linguagem, que permitisse representar os usuários em termos do grau de esforço demandado para a realização do seu próprio trabalho (i.e. fácil versus difícil).

Quando se referiam aos usuários mais fáceis de serem acompanhados, as ACS mobilizavam, com frequência, algumas categorias do sistema oficial, como idosos, crianças e hipertensos. Mas também foram abundantes os relatos de ACS que mobilizavam categorias socioculturais ou comportamentais para descrever como percebem aquilo que consideram um "usuário fácil". Ainda ocorrem casos, embora menos frequentes, de ACS que articularam combinações entre categorias do sistema oficial e informais para descrever os "usuários fáceis". 
Com relação aos usuários considerados difíceis, as entrevistas revelaram que outras categorias, embora dos mesmos sistemas de classificação, eram mobilizadas na caracterização. As categorias do sistema oficial eram mobilizadas com bastante recorrência, mas também apareciam os sistemas de categorização sociocultural relativos a casos de "pacientes difíceis".

O Quadro 1 sistematiza essa interface entre os diferentes sistemas de categorização e a representação dos pacientes - como "fáceis" ou "difíceis" - construída pelas ACS a partir das suas experiências de trabalho e de interação com os usuários do serviço. No quadro são fornecidos exemplos de citações extraídas das entrevistas com as ACS.

Quadro 1

Interface entre sistemas de categorização e representações sobre os usuários

\begin{tabular}{|c|c|c|}
\hline & Fáceis & Difíceis \\
\hline & $\begin{array}{l}\text { "Os idosos sempre tão ali pra te } \\
\text { receber, principalmente os idosos } \\
\text { gostam de receber carinho, gostam de } \\
\text { atenção... Eu tenho uma idosinha que } \\
\text { eu vou visitar ela e eu fico duas horas } \\
\text { com ela, ela me conta desde quando ela } \\
\text { nasceu, e a gente tem que dar atenção } \\
\text { pra eles, principalmente os idosos } \\
\text { porque eles são carentes..." (E6U9). }\end{array}$ & $\begin{array}{l}\text { "(os mais difíceis...) a parte eu acho que } \\
\text { masculina, eu acho que eles não gostam } \\
\text { muito de cuidar, são mais difíceis" } \\
\text { (E8U5). } \\
\text { "Outra família difícil também que eu } \\
\text { tenho na minha micro(área) são pessoas } \\
\text { esquizofrênicas" (E1U9). }\end{array}$ \\
\hline $\begin{array}{l}\text { Categoria } \\
\text { oficial }\end{array}$ & $\begin{array}{l}\text { "As mulheres (...) são mais fáceis de } \\
\text { conversar" (E2U8). } \\
\text { "Os mais fáceis de atender são os hi- } \\
\text { pertensos. Porque como eles já passam } \\
\text { bastante (nas consultas), então eles já } \\
\text { entendem (o serviço), aí a gente orienta } \\
\text { eles pegam e vem... Eles compreendem } \\
\text { mais o serviço da gente" (E6U2). }\end{array}$ & $\begin{array}{l}\text { "Adolescentes é mais difícil, viu? Você } \\
\text { não consegue falar com eles (...). A } \\
\text { gente convida, mas o acesso é mais } \\
\text { difícil" (E3U11). }\end{array}$ \\
\hline
\end{tabular}


Quadro 1

Interface entre sistemas de categorização e representações sobre os usuários (cont.)

\begin{tabular}{|c|c|c|}
\hline & Fáceis & Difíceis \\
\hline $\begin{array}{l}\text { Categoria } \\
\text { sociocultural }\end{array}$ & $\begin{array}{l}\text { "Os mais fáceis são os pobres. Eles } \\
\text { aderem mais porque precisam da } \\
\text { gente." (E7U1). } \\
\text { "O brasileiro, pela comunicação é mais } \\
\text { fácil, pela cultura também é um pouco } \\
\text { mais fácil, e assim, no geral mesmo é o } \\
\text { brasileiro..." (E2U1). }\end{array}$ & $\begin{array}{l}\text { "O mais difícil é o nigeriano. Assim, } \\
\text { o nigeriano não, o mais difícil é os } \\
\text { estrangeiros. Já um grande obstáculo é } \\
\text { a língua, que você não consegue falar, } \\
\text { comunicar com eles... e os tabus deles } \\
\text { também" (E5U11). }\end{array}$ \\
\hline $\begin{array}{l}\text { Categoria } \\
\text { comporta- } \\
\text { mental }\end{array}$ & $\begin{array}{l}\text { "O mais fácil de tratar é aquele paciente } \\
\text { que não precisa pegar no pé. Aquele } \\
\text { que sabe o que tem que fazer, que } \\
\text { sabe a rotina dele, os mais tranquilos" } \\
\text { (E5U2). }\end{array}$ & $\begin{array}{l}\text { "O mais difícil para mim é aquele tipo } \\
\text { reclamão, aquele que reclama de tudo, } \\
\text { que quer tudo na hora, que não quer } \\
\text { esperar" (E3U9). } \\
\text { "Infelizmente na minha microárea não } \\
\text { existe essa divisão de fácil. Todos são } \\
\text { difíceis. São muito fragilizados, eles } \\
\text { estão muito acuados, parecem bichos } \\
\text { acuados, tão muito na defensiva, eles } \\
\text { têm muito medo de muitas coisas, eles } \\
\text { não têm condições" (E1U8). }\end{array}$ \\
\hline $\begin{array}{l}\text { Combinação } \\
\text { de categorias }\end{array}$ & $\begin{array}{l}\text { "Os mais fáceis são os idosos mais } \\
\text { carentes" (E5U9, E3U2). }\end{array}$ & $\begin{array}{l}\text { "Mas com idoso, tem uns que são bens } \\
\text { confusos assim... mas tem uns que } \\
\text { são bens sóbrios também, consegue } \\
\text { conversar e contar as coisas. Mas tem } \\
\text { outros que são mais restritos assim, tem } \\
\text { mais dificuldade" (E4U2). }\end{array}$ \\
\hline
\end{tabular}

Fonte: Entrevistas. Elaboração dos autores.

O exame das entrevistas, assim como os exemplos exibidos no Quadro 1, não nos permite afirmar que haja uma correspondência direta e fixa entre as subcategorias dos sistemas de categorização e a classificação do usuário como "fácil" ou "difícil" a ponto de podermos afirmar, por exemplo, que usuários idosos ou pobres sempre serão classificados como fáceis. O que podemos afirmar, com base nas evidências, é que os sistemas de categorização fornecem a linguagem (categorias descritivas oficiais ou emergentes no local) que permite às ACS construir uma representação do paciente como "fácil" ou "difícil". É por meio dessas categorias que 
se constrói uma narrativa situada (no território ou no tipo de grupo a ser atendido) sobre os usuários, em termos das dificuldades ou facilidades que esses impõem ao serviço a ser realizado pelos ACS.

Isso fica claro quando notamos que as descrições construídas pelas ACS sobre os pacientes entendidos como fáceis tendem a associar categorias (oficiais ou informais) indicativas de um maior grau de passividade e docilidade na relação, seja pela dependência ao serviço ou pela dificuldade de mobilidade e autonomia (como costuma ser o caso de idosos e crianças). Nas narrativas das ACS entrevistadas, esses são os pacientes que oferecem uma maior facilidade para construção de vínculos e adesão, pois, por um lado, tendem a tratar e receber bem as ACS e, por outro, apresentam melhor autocuidado ou necessidade de seguirem os tratamentos e recomendações médicas.

Já os pacientes entendidos como mais difíceis têm suas descrições associadas a categorias que remetem à situação oposta: baixa disponibilidade para o vínculo (como costuma ser o caso de adolescentes e usuários de drogas) ou muita autonomia, maus tratos na relação com os ACS, e falta de autocuidado (frequentemente associadas aos homens e alguns casos de idosos). Nos relatos das ACS, os pacientes "difíceis" aparecem frequentemente associados a descrições como: "os que não escutam nossos conselhos"; "os irresponsáveis que não vão nas consultas e não seguem o tratamento"; "os chatos que só pedem coisas, mas não vão atrás e querem tudo de mão beijada"; "os desobedientes"; "os cabeça-dura"; "os teimosos"; "os indóceis". Essas formas de categorização estão ligadas à ideia de que certos perfis de usuários não seguem as recomendações dadas e tornam-se, portanto, difíceis de serem acompanhados.

Esses achados relativos aos entendimentos sobre pacientes fáceis e difíceis remontam à interpretação, apresentada anteriormente (seção Corresponsabilização e expectativas sobre os usuários"), de que o engajamento dos ACS em relações de coprodução (e os desafios daí decorrentes) incita nos agentes expectativas relativas às características e aos comportamentos dos usuários que sejam mais propícios à boa execução e efetividade do seu trabalho.

Esse achado é reiterado pelo argumento desenvolvido em estudos internacionais sobre casos correlatos. Por exemplo, Tummers (2016) demonstrou que os agentes de implementação priorizam clientes mais 
motivados para atendimento, na medida em que estes podem gerar melhores resultados para o esforço engendrado pelos burocratas. Em outros estudos, revelou-se também como os trabalhadores da linha de frente do serviço público, por vezes, diferenciam os clientes entre "friendly versus hostile" (Sandfort 2000), ou avaliam "whether a client has a large or small chance of 'success'" (Baviskar, 2019). Esta diferenciação está fundamentada na ideia de que usuários mais motivados seriam "moralmente superiores" e, portanto, mais merecedores. Mas, por trás dessa categorização está presente a ideia de que o atendimento a usuários mais motivados traz mais chances de sucesso para o próprio burocrata. Assim, tanto em estudos internacionais quanto no caso dos ACS, percebe-se que a "motivação do usuário" se apresenta como uma possível proxy utilizada pelos agentes para a avaliação da qualidade moral dos primeiros.

Histórias de sucesso e de fracasso: do heroísmo das agentes à culpabilização dos pacientes

Além de fornecer os elementos que levam à percepção dos usuários como "fáceis" ou "difíceis", as interações cotidianas com usuários também se oferecem como arenas de negociação da categorização, nas quais as ACS tentam transformar um paciente que consideram "difícil" em "fácil" (tal como salientado pela terceira perspectiva analítica apresentada na seção "Perspectivas Analíticas sobre a Relação entre Práticas Cotidianas de Implementação e a Produção de Diferenças Sociais"). Isso aparece quando as ACS narraram histórias de sucesso e fracasso em sua experiência profissional. No conjunto de entrevistas analisadas, foram identificadas 60 histórias de sucesso e 56 de fracasso.

Há basicamente três elementos que fundamentam o significado das histórias de sucesso e de fracasso. $\mathrm{O}$ primeiro diz respeito às condições de saúde: as ACS fracassam quando a doença não tinha solução; e têm sucesso quando a doença tem tratamento. O segundo elemento diz respeito ao reconhecimento que as ACS recebem (ou não) pelo trabalho realizado. É sucesso quando conseguem ter seu esforço reconhecido; é fracasso quando são hostilizadas ou maltratadas pelos usuários. O terceiro elemento diz respeito às (in)capacidades das ACS de tirarem usuários da posição de resistentes para aderirem ao serviço. É uma história de sucesso quando conseguem tirar o usuário da posição 
de resistente, e de fracasso quando não conseguem gerar adesão ao serviço. Em geral, nas histórias, estes três elementos se combinam e sobrepõem.

A seguir exemplificamos as histórias de sucesso pelas condições de saúde e pelo reconhecimento:

Um caso de sucesso que eu tive foi uma paciente que, quando eu cadastrei ela, a família dizia que o médico falou que ela tinha uma demência. Aí ela parou de falar. Não falava nada que fazia sentido e a família não sabia por que ela tinha ficado desse jeito. Já tinham feito quatro anos que ela estava assim. A gente foi orientando, fazendo alguns exames, procurando outras especialidades, quando foi descoberto que ela estava com tumor no cérebro enorme. Depois que fez a cirurgia e retirou, ela voltou ao normal (...). E a família dela me recebe muito bem. Quando eu chego lá ela já grita "ai amiga" e vem, me abraça. A gente vê que vale a pena mesmo. Na casa dela eu vou umas 15 vezes no mês, porque toda vez que eu passo na rua chama "vem aqui"... é a família mais próxima que eu tenho (E1U8).

Analisando as histórias de sucesso em nível agregado $(\mathrm{n}=60)$, percebemos que em $75 \%$, apareceram menções relacionando o sucesso à capacidade de produzir adesão; em $70 \%$, menções referentes à cura como parte do sucesso; e em $47 \%$, menções que atribuíam o sucesso ao esforço das ACS e seu reconhecimento.

Para mostrar uma história de fracasso, o exemplo abaixo envolve a não mudança de comportamento por parte dos pacientes:

Tem uma menina, ela tem 14 anos, mora na favela e ficou grávida. Perdeu a criança e não quer qualquer tipo cuidado. O namorado tem 19 anos, ela tem 14. Eu falei "Se previne. Vamos colocar DIU nessa menina". Só que eu vejo que ela não quer. Sabe uma mente bem pequenininha? "Ai, meu namorado quer (ter filho)", "mas você quer?" "não, não quero"., eu falo: "mas por que você não vai cuidar?", "ai, pílula me deixa gorda, DIU não coloquei". Ai você fala meu Deus, essa menina vai ter um monte de filhos e ela não tem estrutura pra isso, ela é muito nova, não estuda, então isso pra mim é bem difícil (...). Eu fico bem pensativa, puxa vida, o que será dessa menina? (...) É um caso muito triste. Ela agora perdeu o bebê. A gente fez várias consultas pra trazer ela na unidade e ela não quis, hoje 
não veio, entendeu? Então eu acho que isso pra mim é bem difícil, uma menina muito nova. (E5U2)

Considerando o conjunto das histórias de fracasso que analisamos $(\mathrm{n}=56)$, identificamos que $62 \%$ continham menções à não adesão do usuário ao tratamento e às recomendações feitas pela ACS; $41 \%$ apontam como fracasso a não cura; $14 \%$ associavam o fracasso a maus tratos ou falta de reconhecimento dos trabalhos das ACS; e 14\% mencionam a falta de apoio das equipes e do sistema de saúde como elemento do fracasso.

Chama atenção nesses dados o fato de que as histórias de fracasso e de sucesso estão fortemente ligadas à capacidade de gerar adesão e conseguir construir vínculos. Elas também reforçam a ideia de que as ACS esperam corresponsabilização por parte dos usuários e os culpam quando isso não acontece. Isso é reiterado pela baixíssima taxa de culpabilização do sistema de saúde nas histórias de fracasso (apenas oito histórias).

Há, nas narrativas de sucesso, uma autopercepção de heroísmo, em que ACS se colocam no papel de salvar o usuário, seja de sua doença, seja de sua sina de não se tratar. As ACS têm sucesso quando conseguem criar condições de tratamento em condições restritas ou quando conseguem convencer os usuários a mudarem sua postura.

As histórias de fracasso, por sua vez, aparecem de forma oposta às de sucesso. Fracasso é não conseguir enfrentar uma situação de doença, não conseguir tirar o paciente de sua condição de "resistente", não conseguir "salvar o usuário" devido às condições restritas ou receber reclamações de pacientes. Com relação ao fracasso, enquanto não alteração da condição de "resistente", a palavra "convencimento" aparece associada à ideia de que "tentei convencer, insisti muito, mas ele não quis e não teve jeito" (E3U3). Também nas histórias de fracasso aparecem narrativas como: "tentei encaminhar a usuária (vítima de violência doméstica), mas ela não vai às consultas" (E4U3); e "não consegui convencer a cadastrada a fazer o tratamento" (E4U1).

Nestes casos, há uma percepção de que as ACS fizeram o que estava ao seu alcance e que, se houve fracasso, a culpa não é delas. As histórias de fracasso, nas quais as ACS foram incapazes de transformar usuários "resistentes" em "aderentes", reforçam a ideia de coprodução, mas também chamam atenção para como o sistema de categorização favorece 
a culpabilização do usuário pelo eventual insucesso no atendimento. De acordo com essa lógica, usuários resistentes que não puderam ser transformados em casos aderentes se localizam em uma zona na qual as ACS não deveriam ser responsabilizadas pelos resultados obtidos, dado que, nestas situações, os usuários insistiram em não se engajar na coprodução, tal como esperado pelos agentes de implementação. Isto é, desenvolve-se uma percepção de que insucessos no atendimento a usuários resistentes não deveriam ser contabilizados como casos de fracasso das ACS, mas sim casos de fracasso do próprio paciente.

\section{CONCLUSÕES}

A presente análise focou as práticas rotineiras de agentes envolvidos em processos de implementação e suas interações com usuários de serviços públicos, buscando compreender de que forma estes contatos se entrelaçam com a produção de diferenças sociais, com potenciais repercussões em termos de dificuldades de acesso ou atendimentos de pior qualidade para públicos que já experimentam situações de vulnerabilidade social e precariedade. Para cumprir este objetivo, nos esforçamos em duas tarefas articuladas, sendo uma teórica e outra empírica.

Primeiramente, sistematizamos os debates na literatura sobre implementação de políticas públicas, com foco no papel e atuação dos agentes de implementação, buscando revelar diferentes perspectivas sobre as conexões entre as práticas cotidianas desses agentes e dinâmicas de diferenciação social e suas implicações para a reprodução de desigualdade. Enquanto a corrente hegemônica chamou atenção para o imperativo da adaptação funcional e os efeitos distributivos das decisões discricionárias, outras abordagens enfatizaram o papel das operações de categorização, julgamentos morais e consequências simbólicas da coprodução. Para além de oferecer um quadro atualizado das discussões nesse campo, a literatura nos municiou com categorias conceituais e analíticas que foram articuladas no esforço empírico subsequente.

Em segundo lugar, buscamos compreender empiricamente as práticas e interações envolvidas em processos de implementação, tendo como objeto de análise a atuação das ACS em suas tentativas de colocar em prática a ESF no município de São Paulo. A execução dessa política é caraterizada pela intensidade das interações dos agentes de implementação e dos usuários do serviço, orientadas pelo princípio da corresponsabilidade, preconizado pela política. Os dados empíricos analisados 
foram oriundos de localidades em que os agentes realizavam boa parte do seu trabalho junto a grupos sociais vulneráveis e famílias vivendo em condições adversas.

Os resultados indicaram que, em contextos de implementação caracterizados simultaneamente por restrições de recursos e capacidades ante a ampla demanda e públicos em diferentes situações de vulnerabilidade, não só a efetivação do princípio da corresponsabilidade tende a ser desafiadora, mas também haverá uma tendência de uso das avaliações sobre o comportamento dos usuários como critério informal para decidir aqueles que merecem ou não receber o serviço de melhor qualidade. No caso estudado, as ACS revelaram considerar como mais merecedores de seus esforços e atenção os usuários que melhor se responsabilizam por seu tratamento, comportam-se adequadamente ou fazem sua parte para o bom andamento dos serviços. Diante de uma percepção de que os usuários não se esforçam o suficiente diante das expectativas de corresponsabilização, as ACS os enquadram como não merecedores.

A percepção dessa dinâmica nos levou a aprofundar a análise em torno das operações de categorização e julgamento conduzidas pelas ACS no cotidiano do seu trabalho com as famílias atendidas. Identificamos que as ACS mobilizam sistemas de categorização oficiais e informais/ práticos. O que essa diversidade demonstra é que, na operação cotidiana da ação das ACS, quando defrontadas com situações reais e complexas para as quais não têm soluções simples, elas recorrem a elementos de segmentação dos usuários que não são típicos dos sistemas oficiais da saúde.

Além disso, percebeu-se como essas categorizações contribuíram para uma segmentação do público atendido em termos de "usuários fáceis" e "usuários difíceis". Os usuários fáceis são entendidos como aqueles com os quais o trabalho tende a ser melhor executado e com os quais se constroem vínculos com maior facilidade, justamente por serem mais dependentes, passivos e dóceis. Já os usuários difíceis, são definidos como complicados em termos da execução do trabalho e da promoção de adesão, são descritos como mais autônomos e menos dedicados ao trato cordial com os agentes e com seu autocuidado. A forma como usuários fáceis e difíceis foram descritos pelas ACS reforçou a percepção de que a implementação de serviços públicos baseados no princípio da corresponsabilização, em cenários marcados por restrições e 
alta vulnerabilidade, incita os agentes de implementação a construírem expectativas e a avaliarem os comportamentos dos usuários como uma forma de orientar suas decisões sobre quem recebe o que, e como o receberá, no decurso do seu trabalho.

Observamos também que a segmentação do público entre usuários fáceis e difíceis cumpriu uma outra função relativa à delimitação da responsabilidade e do escopo de efetividade do trabalho das ACS. A análise das histórias de sucesso indicou que as ACS entendem o seu trabalho como exitoso quando conseguiam converter um usuário difícil em um usuário fácil, isto é, promovendo sua vinculação e adesão ao tratamento. Já as narrativas sobre fracasso remeteram a dificuldades em superar as resistências impostas pelos pacientes, de modo que, tendo feito o que estava ao alcance deles, o insucesso do tratamento e da provisão de serviço não poderia ser atribuído a uma falha dos agentes. Assim, percebe-se como práticas cotidianas de categorização podem cumprir um papel de culpabilização do usuário pelo insucesso no tratamento. Nessa lógica de segmentação do público, aqueles pacientes difíceis que não puderam ser convertidos em aderentes passam a se localizar em um espaço no qual os ACS não deveriam ser responsabilizados pelo seu desempenho ou resultados obtidos, dado que nestas situações os usuários insistiram em não se engajar na coprodução, pelo menos não da forma esperada pelos agentes de implementação.

Como já reconhecido pela literatura internacional, a mobilização e uso cotidiano desses sistemas de categorização por parte dos agentes de implementação pode repercutir em dinâmicas de discriminação, exclusão ou desatenção a grupos vulneráveis (Harrits, 2019). Esses sistemas de categorização revelam um trabalho de construção de fronteiras simbólicas (boundary work - Lamont, 1992, 2002) que os agentes desempenham sobre o público atendido. Por meio desses esforços, eles dividem o público atendido de forma a organizar uma oferta funcional diante dos desafios enfrentados, mas apoiada em diferenciações sociais. De um lado, usuários "aderentes", com os quais foi possível construir vínculos, tornam-se merecedores e recebem mais do que o serviço demandado inicialmente. De outro lado, os usuários "resistentes" tornam-se vítimas de uma profecia autorrealizada: como inicialmente não aderem/obedecem ao que os profissionais recomendam, tornam-se não merecedores de serviços básicos e, menos ainda, de serviços adicionais. 
Isso se torna crítico quando entendemos que sistemas de categorização mobilizam tanto aspectos relativos às questões de saúde quanto julgamentos morais sobre o comportamento das pessoas. Usuários de droga, pacientes com transtornos psiquiátricos, ou gestantes adolescentes, por exemplo, foram frequentemente classificados como resistentes, difíceis e fortemente relacionados às histórias de fracasso. A condição de saúde desses públicos exigiria, justamente, um olhar mais atento e cuidadoso por parte dos profissionais de saúde, pois a não adesão pode ser entendida menos como uma escolha individual e mais como uma evidência da vulnerabilidade vivida pelos usuários. A dificuldade de acesso (ou o atendimento de baixa qualidade), no caso desses públicos, pode representar um fator importante para a manutenção ou deterioração de sua condição social através de um ciclo vicioso de acumulação de desvantagens.

(Recebido para publicação em 30 de maio de 2019)

(Reapresentado em 11 de outubro de 2019)

(Aprovado para publicação em 7 de dezembro de 2019) 


\section{Gabriela Spanghero Lotta, Roberto Rocha Coelho Pires}

\section{NOTAS}

1. Definimos práticas cotidianas de implementação como os padrões de ação desempenhados pelos trabalhadores do Estado no exercício contínuo de execução das políticas e serviços públicos nos quais estão envolvidos. Em linha com Sharma e Gupta (2006), abordamos essas práticas burocráticas, aparentemente banais, como elementos fundamentais da constituição cultural dos Estados e das formas de exercício de poder em relação à sociedade.

2. O foco da análise se restringe aos funcionários que atuam nas linhas de frente do serviço público e não contempla a atuação de outros estratos da estrutura burocrática do Estado (como o médio e o alto escalão).

3. Importante notar que o foco de Lamont é em como as pessoas diferenciam elas mesmas dos outros (ou seja, uma diferenciação entre "nós" e "eles"). Nesse estudo mobilizamos a noção de "boundary work" (Lamont, 1992) para pensar como agentes envolvidos em processos de implementação constroem a diferenciação simbólica dos públicos que atendem por força do seu trabalho.

4. A noção de coprodução aqui utilizada vem da sociologia interacionista de Goffman (1968) e não se confunde com aquela disseminada em estudos do campo da implementação de políticas, envolvendo diferentes formas e arranjos de parceria entre atores públicos, privados ou associações civis (Evans, 1996; Olstrom, 1996).

5. De forma semelhante a diversas experiências internacionais de saúde comunitária que buscam aproximar políticas de saúde ao cotidiano dos usuários (Medcalfe e Nunes, 2018).

6. Como o Programa de Atenção Integral às Famílias, do Sistema Único de Assistência Social (Jaccoud e Abreu, 2019).

7. As entrevistas foram gravadas, transcritas e analisadas com suporte do software NVivo. Cada entrevista passou por duas fases de codificação, inspiradas na abordagem grounded theory (Charmaz, 2006). Primeiro, um processo de codificação linha a linha, nomeando categorias de usuários e julgamentos. Em seguida, reorganização das categorias encontradas considerando elementos mais frequentes e que respondiam às perguntas de pesquisa (ex.: usuários fáceis e difíceis, tipos de julgamento, processos de encaminhamento etc.).

8. Ao longo da análise apresentaremos os trechos das entrevistas que evidenciam as interpretações e argumentos desenvolvidos. As entrevistas foram numeradas pelo número do entrevistado (E) e o número da UBS (U).

9. Esses achados relativos à operação de sistemas de categorização paralelos, formais e informais, é consistente com a literatura internacional que analisou outros tipos de agentes de implementação (Moller e Stone, 2013).

10. O termo "resistente" apareceu associado aos "usuários difíceis" em $64 \%$ das entrevistas. 


\section{Categorizando Usuários "Fáceis" e "Difíceis"}

\section{REFERÊNCIAS}

BOURDIEU, Pierre. (1972), Esquisse d'une théorie de la pratique. Genebra: Librairie Droz.

BAVISKAR, Siddhartha. (2019), "Who creams? Explaining the cream-skimming behavior of public school teachers in Denmark from a street-level bureaucracy perspective". International Public Management Journal, v. 22, n. 3, pp. 524-559.

BRASIL. (1997), Saúde da Família: uma estratégia para a reorientação do modelo assistencial. Brasília: Ministério da Saúde, Secretaria de Assistência à Saúde.

BRODKIN, Evelyn. (2012), "Reflections on street-level bureaucracy: past, present, and future". Public Administration Review, v. 72, pp. 940-949.

(1990), "Implementation as policy politics". In: D. Palumbo; D. Calista (eds.), Implementation and the policy process. Westport, CT: Greenwood Press, pp. 107-131.

; MAJMUNDAR, Malay. (2010), "Administrative exclusion: organizations and the hidden costs of welfare claiming". Journal of Public Administration Research and Theory, v. 20 , n. 4 , pp. $827-848$.

BRITO, Simone; SCHUCH, Patrice. (2019), “Apresentação ao Dossiê Burocracias, Cotidiano e Valores". Revista Brasileira de Sociologia, v. 07, n. 15, pp. 5-8.

CHARMAZ, Kathy. (2006), Constructing grounded theory: a practical guide through qualitative analysis. London: Sage Publications.

DAVIS, Kenneth. (1969), Discretionary Justice. Baton Rouge: Louisiana State University Press.

DUBOIS, Vincent. (1999), La vie au guichet. Relation administrative et traitement de la misère. Paris: Economica.

DUROSE, Catherine. (2011), “Revisiting Lipsky: Front-Line Work in UK”. Political Studies, v. 59, n. 4, pp. $978-995$.

ELIAS, Norbert. (1994), A sociedade dos indivíduos. Rio de Janeiro: Jorge Zahar Ed.

ELLIS, Kathryn. (2011), "'Street-level Bureaucracy' revisited: the changing face of frontline". Social Policy \& Administration, v. 45, n. 3, pp. 221-244.

EPP, Charles; MAYNARD-MOODY, Steven; HAIDER-MARKEL, Donald. (2014), Pulled over: how police stops define race and citizenship. Chicago: The University of Chicago Press.

GELINSKI. Carmen. (2011), “A questão da co-responsabilidade prevista na estratégia saúde da família". Política e Sociedade, v. 10, n. 19, pp. 97-114.

GOETZ, Anne Marie. (2001), Women development workers: implementing rural credit programmes in Bangladesh. New Delhi: Sage Publications.

GOFFMAN, Erwin. (1961), Asylums: essays on the social situation of mental patients and other inmates. New York: Anchor Books/Doubleday.

GOODSELL, Charles. (1981), The public encounter. Bloomington, IN: Indiana University Press.

HARRITS, Gitte; MØLLER, Marie. (2013), "Prevention at the front line: how home nurses, pedagogues, and teachers transform public worry into decisions on special efforts". Public Management Review, v. 16, n. 4, pp. 447-480. 


\section{Gabriela Spanghero Lotta, Roberto Rocha Coelho Pires}

HARRITS, Gitte. (2019), "Stereotypes in context: how and when do street-level bureaucrats use class stereotypes?". Public Administration Review, v. 79, n. 1, pp. 93-103.

HILL, Michael; HUPE, Peter. (2014), Implementing public policy: an introduction to the study of operational governance. London: Sage Publications.

HILL, Michael; HUPE, Peter; BUFFAT, Aurelien. (2015), Understanding street-level bureaucracy. Bristol: University of Bristol.

HUPE, Peter; HILL, Michael. (2007), "Street-Level bureaucracy and public accountability". Public Administration, v. 85, n. 2, pp. 279-299.

JACCOUD, Luciana; ABREU, Maria Cristina. (2019), “Entre o direito e a culpabilização das famílias: o que pensam os trabalhadores do Sistema Único de Assistência Social (SUAS) sobre as ofertas e os beneficiários". In: R. Pires (ed.), Implementando desigualdades: reprodução de desigualdades, na implementação de políticas públicas. Rio de Janeiro: IPEA, pp. 485-504.

KORTEWEG, Anna. (2003), "Welfare reform and the subject of the working mother: 'get a job, a better job, then a career'". Theory and Society, v. 32, n. 4, pp. 445-480.

LAHIRE, Bernard. (2003), "Crenças coletivas e desigualdades culturais". Educação \& Sociedade, v. 24, n. 84, pp. 983-995.

LAMONT, Michelle. (1992), Money, morals, and manners: the culture of the French and American Upper-Middle Class. Chicago: University of Chicago Press.

(2000), The dignity of working men: morality and the boundaries of race, class, and immigration. New York: Russell Sage Foundation.

(2017), Prisms of inequality: moral boundaries, exclusion, and academic evaluation. Ensaio para apresentação na Praemium Erasmianum Foundation por ocasião da premiação Erasmus Prize para Michelle Lamont, Amsterdam, Novembro.

LIPSKY, Michael. (1969), Toward a theory of street-level bureaucracy. Trabalho apresentado na reunião anual da American Political Science Association, New York, 2-6 de setembro. Institute for Research on Poverty, University of Wisconsin, Madison, Wisconsin.

[1980] (2010), Street level bureaucracy: dilemmas of the individual in public services. New York: Russell Sage Foundation.

LOTTA, Gabriela. (2015), Burocracia e implementação de políticas de saúde. Rio de Janeiro: Editora Fiocruz.

MAYNARD-MOODY, Steven; MUSHENO, Michael. (2003), Cops, teachers, counselors: narratives of street-level judgment. Ann Arbor: University of Michigan Press.

. (2012), "Social equities and inequities in practice: street-level workers as agents and pragmatists". Public Administration Review, v. 71, Edição Especial em homenagem a H. George Frederickson, pp. S16-S23.

MENICUCCI, Telma; MARQUES, Alisson. (2016), "Cooperação e coordenação na implementação de políticas públicas: o caso da saúde". DADOS - Revista de Ciências Sociais, v. 59 , n. 3, pp. 823-865. 


\section{Categorizando Usuários "Fáceis" e "Difíceis"}

MEDCALF, Alexander; NUNES, João. (2018), “Visualizing primary health care: World Health Organization Representations of Community Health Workers, 1970-89". Medical History, v. 62 , n. 4 , pp. 401-424.

MINISTÉRIO DA SAÚDE. (2018), Site institucional: www.saude.gov.br. Acessado em $\operatorname{dez} / 2018$.

MØLLER, Marie. (2016), “'She isn't someone I associate with Pension' - A vignette study of professional reasoning". Professions \& Professionalism, v. 6, n. 1, https:/ /doi.org/10.7577/ pp.1353.

; STONE, Deborah. (2013). "Disciplining disability under Danish active labour market policy". Social Policy \& Administration, v. 47, n. 5, pp. 586-604.

NIELSEN, Vibeke. (2006), "Are street-level bureaucrats compelled or enticed to cope?" Public Administration, v. 84, n. 4, pp. 861-889.

NUNES, João; LOTTA, Gabriela. (2019), “Discretion, power and the reproduction of inequality in health policy implementation: practices, discursive styles and classifications of Brazil's community health workers". Social Science $\mathcal{E}$ Medicine, v. 242, pp. 1-8.

OORSCHOT, Wim. (2008), "Solidarity towards immigrants in European welfare states". International Journal of Social Welfare, v. 17, n. 1, pp. 3-14.

PIRES, Roberto. (2009), “Estilos de implementação e resultados de políticas públicas: fiscais do trabalho e o cumprimento da lei trabalhista no Brasil". DADOS - Revista de Ciências Sociais, v. 52, n. 3, pp. 734-769.

(2011), "Beyond the fear of discretion: flexibility, performance, and accountability in the management of regulatory bureaucracies". Regulation $\mathcal{E}$ Governance, v. 5, n. 1, pp. 45-71.

(2017), "Sociologia do guichê e implementação de políticas públicas". Revista Brasileira de Informação Bibliográfica em Ciências Sociais - BIB, n. 81, pp. 5-24.

. (2019), Implementando desigualdades: reprodução de desigualdades na implementação de políticas públicas. Rio de Janeiro: IPEA.

PORTILLO, Sharon; RUDES, Danielle. (2014), "Construction of justice at the street level". Annual Review of Law and Social Science, v. 10, pp. 321-334.

ROSENTHAL, Patrice; PECCEI, Riccardo. (2005), "The social construction of clients by service agents in reformed welfare administration". Human Relations, v. 59, n. 12, pp. 1633-1658.

REINEHR, Jaciene. (2019), Silêncios e confrontos: a saúde da população negra em burocracias do Sistema Único de Saúde (SUS). Tese (Doutorado em Sociologia e Antropologia) Universidade Federal do Rio de Janeiro, Rio de Janeiro.

SANDFORT, Jodi. (2000), "Moving beyond discretion and outcomes: Examining public management from the front lines of the welfare system". Journal of Public Administration Research and Theory, v. 10, n. 4, pp. 729-756.

SCHNEIDER, Anne; INGRAM, Helen. (2005), Deserving and entitled: social construction and public policy. Albany, NY: State University of New York Press.

SHARMA, Aradhana; GUPTA, Akhil. (2006), The anthropology of the state: a reader. London: Blackwell Publishing. 


\section{Gabriela Spanghero Lotta, Roberto Rocha Coelho Pires}

SIBLOT, Yasmine. (2006), Faire valoir ses droits au quotidien: les services publics dans les quartier populaire. Paris: Presses de Sciences-Po.

SILBEY, Susan. (1981), "Case processing: Consumer protection in an Attorney General's office". Law \& Society Review, v. 15, n. 3-4, pp. 849-910.

(2011), "The sociological citizen: pragmatic and relational regulation in law and organizations". Regulation \& Governance, v. 5, n. 1, pp. 1-17.

SILVA, Joana; DALMASO, Ana. (2002), Agente comunitário de saúde: o ser, o saber, o fazer. Rio de Janeiro: Fiocruz.

SMALL, Mario Luiz. (2009), "How many cases do I need? On science and the logic of case selection in field-based research". Ethnography, v. 10, n. 1, pp. 5-38.

THOMANN, Eva; RAPP, Carolin. (2018), “Who deserves solidarity? Unequal treatment of immigrants in Swiss Welfare Policy Delivery". Policy Studies Journal, v. 46, n. 3, pp. 531-552.

TROST, Jan. (1986), “Statistically nonrepresentative stratified sampling: a sampling technique for qualitative studies". Qualitative Sociology, v. 9, n. 1, pp. 54-57.

TUMMERS, Lars. (2017), "The relationship between coping and job performance". Journal of Public Administration Research and Theory, v. 27, n. 1, pp. 150-162.

et al. (2015), "Coping during public service delivery: a conceptualization and systematic review of the literature". Journal of Public Administration, Research and Theory, v. 25, n. 4, pp.1099-1126.

WELLER, Jean-Marc. (1999), L'état au guichet: sociologie cognitive du travail et modernisation administrative des services publics. Paris: Desclée de Brouwer.

WILSON, James Q. (1968), Varieties of Police Behavior: the management of law and order in eight communities. Cambridge: Harvard University Press.

WINTER, Soren. (2003), Political control, street-level bureaucrats and information asymmetry in regulatory and social policies. Trabalho apresentado na reunião anual da Association for Policy Analysis and Management, Washington, 6-8 de novembro.

WORCMAN, Nicola; MORGANTI, Rafael. (2019), “O proibicionismo introjetado: reprodução da violência e exclusão entre os usuários de um Centro de Atenção Psicossocial Álcool e outras Drogas". In: R. Pires (ed.), Implementando desigualdades: reprodução de desigualdades na implementação de políticas públicas. Rio de Janeiro: IPEA, pp. 701-718. 


\section{RESUMO \\ Categorizando Usuários "Fáceis" e "Difíceis": Práticas Cotidianas de Implementação de Políticas Públicas e a Produção de Diferenças Sociais}

Este artigo aborda como as práticas cotidianas de agentes envolvidos em processos de implementação de políticas públicas se entrelaçam com a produção da diferenciação social dos públicos atendidos. Parte-se de uma sistematização de perspectivas analíticas presentes no debate internacional sobre implementação de políticas públicas que, então, são colocadas em diálogo com o estudo empírico da implementação da Estratégia Saúde da Família no município de São Paulo, com foco na atuação dos Agentes Comunitários de Saúde. Revela como as diferenças sociais penetram o mundo das políticas públicas por meio da centralidade de práticas de categorização e julgamento dos usuários dos serviços. Essas práticas constituem um esforço de delimitação de fronteiras simbólicas que permite aos agentes operarem uma segmentação não oficial do público atendido, classificandoos entre usuários "fáceis" e "difíceis". Os achados indicam que a diferenciação social produzida mescla elementos de natureza funcional com elementos morais associados a uma avaliação sobre a (in)adequação do comportamento dos usuários, com potenciais implicações para dinâmicas mais amplas de reprodução de desigualdades sociais.

Palavras-chave: implementação de políticas públicas; burocracia de nível de rua; desigualdades; políticas sociais; diferenças sociais

\section{ABSTRACT \\ Categorizing "Easy" and "Difficult" Users: Everyday Practices of Public Policy Implementation and the Production of Social Differences}

This article addresses how the daily practices of agents involved in public policy implementation processes are intertwined with the production of social differentiation of the types of publics served. We start from a systematization of analytical perspectives that are part of the international debate on the implementation of public policies. Then, we aim to establish a dialogue between these perspectives and the empirical study of the implementation of the Family Health Strategy in the city of São Paulo, focusing on the performance of Community Health Agents. We proceed to reveal how social differences enter the world of public policies through the centrality of categorization and judgment practices of service users. These practices constitute an effort to delimit symbolic borders that allow agents to operate an unofficial segmentation of the public served, classifying them as "easy" or "difficult" users. The findings indicate that the social differentiation produced 


\section{Gabriela Spanghero Lotta, Roberto Rocha Coelho Pires}

mixes elements of a functional nature with moral elements associated with an assessment of the adequacy or not of users' behavior, with potential implications for the broader dynamics of reproduction of social inequalities.

Keywords: implementation of public policies; street-level bureaucracy; inequalities; social policies; social differences

\section{RÉSUMÉ \\ Catégoriser les Utilisateurs "Faciles" et "Difficiles": Pratiques Quotidiennes de Mise-en-CEuvre des Politiques Publiques et Production de Différences Sociales}

Cet article explique comment les pratiques quotidiennes des agents impliqués dans les processus de mise-en-œuvre des politiques publiques sont liées à la production de différenciation sociale du public servi. Il part d'une systématisation des perspectives analytiques présentes dans le débat international sur la mise-en-œuvre des politiques publiques, qui sont ensuite mises en dialogue avec l'étude empirique de la mise-en-œuvre de la stratégie de santé familiale dans la municipalité de São Paulo, en se concentrant sur la performance des agents communautaires. On révèle comment les différences sociales pénètrent dans le monde des politiques publiques à travers la centralité des pratiques de catégorisation et de jugement des utilisateurs de services. Ces pratiques constituent un effort pour délimiter des frontières symboliques qui permettent aux agents d'opérer une segmentation non officielle du public servi, en les classant entre utilisateurs "faciles" et "difficiles". Les résultats indiquent que la différenciation sociale produite mélange des éléments de nature fonctionnelle avec des éléments moraux associés à une évaluation de l' (in) adéquation du comportement des utilisateurs, avec des implications potentielles pour les dynamiques plus larges de reproduction des inégalités sociales.

Mots-clés: mise-en-œuvre des politiques publiques; bureaucratie au niveau de la rue; inégalités; politiques sociales; différences sociales

\section{RESUMEN}

Categorizando Usuarios "Fáciles" y "Difíciles": Prácticas Cotidianas de Implementación de Politicas Públicas y la Producción de Diferencias Sociales

Este artículo aborda cómo las prácticas cotidianas de agentes involucrados en procesos de implementación de políticas públicas se entrelazan con la producción de la diferenciación social de los públicos atendidos. Se parte de una sistematización de perspectivas analíticas presentes en el debate internacional sobre implementación de políticas públicas que, entonces, son colocadas en diálogo con el estudio 
empírico de la implementación de la Estrategia Salud de la Familia en el municipio de São Paulo, con énfasis en la actuación de los Agentes Comunitarios de Salud. El artículo revela cómo las diferencias sociales penetran el mundo de las políticas públicas por medio de la centralidad de prácticas de categorización y juzgamiento de los usuarios de los servicios. Esas prácticas constituyen un esfuerzo de delimitación de fronteras simbólicas que permite a los agentes operar en una segmentación no oficial del público atendido, clasificándolos entre usuarios "fáciles" y "difíciles". Los hallazgos indican que la diferenciación social producida mezcla elementos de naturaleza funcional con elementos morales asociados a una evaluación sobre la (in)adecuación de comportamiento de los usuarios, con implicaciones potenciales para dinámicas más amplias de reproducción de desigualdades sociales.

Palabras clave: implementación de políticas públicas; burocracia a nivel de calle; desigualdades; políticas sociales; diferencias sociales 